\title{
PERLINDUNGAN HUKUM TERHADAP PEKERJA MIGRAN INDONESIA DI LUAR NEGERI ${ }^{*}$
}

\author{
Oleh: \\ A. A. Titah Ratihtiari* \\ I Wayan Parsa** \\ Program Kekhususan Hukum Perdata Fakultas Hukum \\ Universitas Udayana
}

\begin{abstract}
Abstrak
Tulisan ini memiliki latar belakang yang berkaitan dengan perlindungan hukum terhadap Pekerja Migran Indonesia yang bekerja di luar negeri, dengan tujuan untuk menganalisis upaya hukum dalam perlindungan Pekerja Migran Indonesia di luar negeri serta untuk mengkaji secara lebih dalam bagaimanakah jaminan sosial terhadap Pekerja Migran Indonesia menurut Undang-Undang Nomor 18 Tahun 2017 tentang Perlindungan Pekerja Migran Indonesia. Menggunakan metode penulisan berdasarkan penelitian hukum normatif yang disebut juga sebagai penelitian perpustakaan, studi dokumen, atau penelitian hukum doktriner. Perlindungan hukum terhadap Pekerja Migran Indonesia yang diupayakan oleh pemerintah berupa terciptanya aturan hukum yang diharapkan dapat melindungi Pekerja Migran Indonesia saat bekerja di luar negeri. Namun upaya perlindungan hukum tersebut masih dianggap lemah, dikarenakan masih saja ada banyak kasus yang menimpa Pekerja Migran Indonesia. Pemerintah berkewajiban melindungi semua warga negaranya tanpa terkecuali baik yang sedang berada di dalam ataupun di luar negeri. Adapun ke depannya pemerintah dapat mengkaji kembali peraturan mengenai perlindungan Pekerja Migran Indonesia sehingga tidak ada lagi kasus yang mengancam Pekerja Migran Indonesia.
\end{abstract}

Indonesia.

Kata Kunci: Perlindungan Hukum, Tenaga Kerja

\section{Abstrack}

This paper is motivated by legal issues concerning legal protection for Indonesian immigrant workers who working abroad.

*Karya ilmiah ini merupakan makalah ilmiah di luar ringkasan skripsi

${ }^{* *}$ Penulis merupakan mahasiswa pada Fakultas Hukum Universitas Udayana, penulis dapat dihubungi melalui aaratihtiari@yahoo.com

${ }^{* * *}$ Penulis merupakan pengajar pada Fakultas Hukum Universitas Udayana, penulis dapat dihubungi melalui wayan.parsa@yahoo.co.id 
This paper aims to analyze the forms of legal protection that the government give to Indonesian immigrant workers and to reviewing more about how the government gonna tackles the problems that happened to Indonesian immigrant workers who working abroad. This paper using a type of normative legal research that based on the literature. Legal protection that given by the government for Indonesian immigrant workers in the form of creating the rules which are expected to protect the Indonesian immigrant workers who working abroad. But that legal protection is considered weak, because there are still many cases that happened to Indonesian immigrant workers. For examples are the cases of persecution, murder, raped, etc. The government who has the main responsibility about this, must be always protecting the citizens in or out the state however the effort. In the future, the government is expected to reviewing again the rules about legal protection that is considered weak so the cases are not gonna happen again to Indonesian immigrant workers.

\section{Workers.}

Keywords: Legal Protection, Indonesian Immigrant

\section{PENDAHULUAN}

\subsection{Latar Belakang Masalah}

Indonesia merupakan salah satu negara yang dinilai sedang berkembang pada saat ini. Hal tersebut menyebabkan Indonesia mengalami beberapa permasalahan, salah satunya berkaitan dengan kependudukan. Setiap tahun Indonesia mengalami peningkatan penduduk yang signifikan sehingga berpengaruh terhadap penambahan tenaga kerja. Namun penambahan tenaga kerja tersebut tidak dapat tersalurkan dengan baik dikarenakan lapangan kerja yang tersedia justru terbatas sehingga hal ini menimbulkan masalah lain yaitu pengangguran yang juga bertambah.

Banyaknya pengangguran yang ada di Indonesia menyebabkan para pencari kerja tersebut bermigran, baik itu bermigran dari suatu daerah ke daerah lain, maupun bermigran hingga ke luar negeri yang selanjutnya disebut sebagai pekerja migran Indonesia atau lebih dikenal dengan sebutan TKI (Tenaga 
Kerja Indonesia). Menurut Pasal 1 angka (2) UU No. 18 Tahun 2017 tentang Perlindungan Pekerja Migran Indonesia, "Pekerja Migran Indonesia adalah setiap warga negara Indonesia yang akan, sedang, atau telah melakukan pekerjaan dengan menerima upah di luar wilayah Republik Indonesia." Dengan adanya tenaga kerja yang bermigran ke luar negeri, tentu pemerintah Indonesia sangat diuntungkan, karena selain bisa mengurangi jumlah pengangguran di dalam negeri, juga bisa meningkatkan devisa negara. Dalam prakteknya, tidak semua impian atau harapan tersebut bisa dicapai dengan sempurna, hal ini dialami oleh banyak tenaga kerja Indonesia yang bermigran ke luar negeri, seperti ke Malaysia, Brunei, Arab Saudi, dll. Di negara-negara tujuan tersebut banyak tenaga kerja mengalami permasalahan dimana mereka diperlakukan tidak semestinya oleh sang majikan.

Sebagai contoh nyata ialah pada tahun 2010, tanpa sebab yang jelas Sumiyati, TKI asal Nusa Tenggara Barat yang pada saat itu bekerja di Arab Saudi, dianiaya secara sadis oleh majikan perempuannya kemudian dibakar hidup-hidup dan jasadnya yang hangus dibiarkan begitu saja di lantai atas rumah. ${ }^{1}$ Pada tahun 2017, Wasni seorang TKI asal Kabupaten Cirebon, Jawa Barat menjadi korban penyiksaan majikannya di Riyadh, Saudi Arabia, korban juga tidak diberikan gaji selama hampir empat tahun bekerja. ${ }^{2}$ Pada tahun 2018, Adelina Lisao seorang TKI asal Nusa

\footnotetext{
${ }^{1}$ Puthut Dwi Putranto Nugroho, 2018, "Kisah Sumiyati, TKI dari Grobogan yang Tewas Dianiaya Majikannya di Arab Saudi", URL: https://regional.kompas.com/read/2018/01/11/09060501/kisah-sumiyati-tkidari-grobogan-yang-tewas-dianiaya-majikannya-di-arab?page $=$ all,,$\quad$ diakses tanggal 17 Mei 2019.

2 Toiskandar, 2017, "Wasni TKI Asal Cirebon Kerap Disiksa dan Tak Digaji Selama 45 Bulan", URL: https://daerah.sindonews.com/read/1251784/21/ wasni-tki-asal-cirebon-kerap-disiksa-dan-tak-digaji-selama-45-bulan-15089874 $\underline{46}$, diakses tanggal 17 Mei 2019.
} 
Tenggara Timur yang meninggal di Penang akibat kurang gizi dan luka-luka yang diduga disebabkan aksi kekerasan majikan, dan tentu masih banyak lagi kasus-kasus lainnya. ${ }^{3}$

Berdasarkan beberapa contoh kasus yang telah disebutkan di atas, maka perlu adanya suatu perlindungan yang mampu mengatasi persoalan atau permasalahan yang ada selama ini terkait dengan penempatan dan perlindungan Pekerja Migran Indonesia, baik itu sebelum berangkat, selama bekerja, maupun setelah kembali pulang ke Indonesia. Diperlukan adanya koordinasi antar instansi yang terkait mulai dari Pemerintah Daerah, Departemen Tenaga Kerja dan Trasmigrasi, Badan Nasional Penempatan dan Perlindungan Tenaga Kerja Indonesia (BNP2TKI), serta Departemen Luar Negeri agar tidak terjadi tumpang tindih wewenang dan saling tarik ulur kekuasaan antar lembaga. Dengan demikian pemerintah bisa memonitor setiap langkah perjalanan Pekerja Migran Indonesia tersebut, sehingga seandainya terjadi permasalahan bisa ditelusuri dimana letak kesalahan sebenarnya.

Bekerja merupakan hak asasi manusia dan oleh karena itu negara diminta berperan aktif untuk memberikan perlindungan bagi warga negaranya. ${ }^{4}$ Setiap tenaga kerja selama bekerja di samping memiliki kewajiban, juga memiliki hak dan kesempatan yang sama tanpa adanya diskriminasi baik itu di dalam negeri maupun di luar negeri. ${ }^{5}$ Berdasarkan uraian

\footnotetext{
${ }^{3}$ BBC News Indonedia, 2018, Adelina: TKI yang meninggal di Malaysia akibat kurang gizi dan luka-luka membuat 'marah bangsa', https://www.bbc.com/indonesia/trensosial-43044843, diakses tanggal 17 Mei 2019.

4 Lukas Banu, 2018, "Implementasi Hukum Pasal 35 Undang-Undang Nomor 39 Tahun 2004 dalam Program Recognised Seasonal Employment", Jurnal Magister Hukum Udayana, Bali.

${ }^{5}$ I Wayan Agus Vijayantera, 2016, "Pengaturan Tunjangan Hari Raya Keagamaan sebagai Hak Pekerja Setelah Diterbitkan Peraturan Menteri Tenaga Kerja Nomor 6 Tahun 2016", Jurnal Hukum Kertha Patrika Fakultas Hukum Universitas Udayana, Bali.
} 
sebelumnya mengenai banyaknya kasus-kasus menyedihkan yang dialami oleh Pekerja Migran Indonesia di luar negeri, maka selanjutnya perlu dibahas tentang peranan pemerintah Indonesia dalam melindungi Pekerja Migran Indonesia di luar negeri, karena selama ini belum ada penanganan masalah TKI secara maksimal. Mengingat masih saja marak terjadi berbagai permasalahan Pekerja Migran Indonesia di luar negeri yang diperlakukan tidak manusiawi atau tidak sebagaimana mestinya oleh majikannya baik itu dianiaya, dibunuh, diusir, mengalami pelecehan seksual hingga pemerkosaan, bunuh diri, pekerjaan tidak sesuai perjanjian kerja, gaji tak kunjung dibayar, dipenjara, sakit akibat kerja, dan masih banyak lagi seperti tidak ada habisnya. ${ }^{6}$

\subsection{Rumusan Masalah}

Berdasarkan latar belakang yang telah diuraikan di atas, maka terdapat dua rumusan masalah yang akan dibahas yaitu :

1. Bagaimanakah upaya pemerintah dalam mewujudkan perlindungan hukum bagi Pekerja Migran Indonesia melalui program Desa Migran Produktif?

2. Bagaimanakah jaminan sosial terhadap Pekerja Migran Indonesia menurut UU No. 18 Tahun 2017 tentang Perlindungan Pekerja Migran Indonesia?

\subsection{Tujuan Penulisan}

Tujuan disusunnya tulisan ini ialah untuk menganalisis upaya pemerintah dalam mewujudkan perlindungan hukum bagi Pekerja Migran Indonesia melalui program Desa Migran Produktif

6 Erwan Baharudin, 2007, "Perlindungan Hukum Terhadap TKI di Luar Negeri Pra Pemberangkatan, Penempatan, dan Purna Penempatan", Jurnal Universitas Indonesia Esa Unggulan, Jakarta Barat. 
serta untuk mengkaji secara lebih dalam bagaimanakah jaminan sosial terhadap Pekerja Migran Indonesia menurut UU No. 18 Tahun 2017 tentang Perlindungan Pekerja Migran Indonesia.

\section{ISI MAKALAH}

\subsection{Metode Penelitian}

Metode penulisan yang digunakan dalam tulisan ini ialah berdasarkan penelitian hukum yang bersifat normatif (normative legal research). Sebutan lain dari penelitian hukum normatif yaitu penelitian perpustakaan, studi dokumen, atau penelitian hukum doktriner ${ }^{7}$ dimana memiliki sumber yang diperoleh melalui bahan hukum primer dan juga bahan hukum sekunder. Pertama-tama, bahan hukum primer merupakan suatu bahan hukum yang berotoritas (autoritatif) ${ }^{8}$, berupa peraturan perundang-undangan. Sedangkan bahan hukum sekunder adalah seluruh publikasi atas hukum yang merupakan dokumen informal/tidak resmi. 9 Sumbernya didapat melalui bahan hukum yang sebelumnya telah dikumpulkan dan diteliti, dan tentunya juga berkaitan dengan permasalahan di dalam penulisan ini ${ }^{10}$, berupa buku-buku hukum, jurnal-jurnal hukum, dan juga internet yang berkaitan.

\subsection{Hasil Pembahasan}

\subsubsection{Upaya Pemerintah dalam Mewujudkan Perlindungan Hukum bagi Pekerja Migran Indonesia melalui Program Desa Migran Produktif}

7 Suratman dan H. Philips Dillah, 2015, Metode Penelitian Hukum, Alfabeta, Bandung, h. 51.

${ }^{8}$ Zainuddin Ali, 2014, Metode Penelitian Hukum, Sinar Grafika, Jakarta, h. 47 .

${ }^{9}$ Ibid, h. 54.

${ }^{10}$ Bambang Sunggono, 2010, Metodelogi Penelitian Hukum, Rajawali Pers, Jakarta, h. 86. 
Hingga saat ini pemerintah menyatakan komitmen tinggi untuk melindungi tenaga kerja Indonesia (TKI) atau kini disebut Pekerja Migran Indonesia (PMI) yang bekerja di luar negeri. Perlindungan tersebut bahkan dimulai dari perekrutan sampai TKI kembali ke tanah air.

Perlindungan hukum adalah segala upaya pemenuhan hak dan pemberian bantuan untuk memberikan rasa aman kepada saksi dan/atau korban, perlindungan hukum korban kejahatan sebagai bagian dari perlindungan masyarakat, dapat diwujudkan dalam berbagai bentuk, seperti melalui pemberian restitusi, kompensasi, pelayanan medis, dan bantuan hukum. ${ }^{11}$ Menurut Philipus M. Hadjon, perlindungan hukum adalah perlindungan akan harkat dan martabat, serta pengakuan terhadap hak-hak asasi manusia yang dimiliki oleh subyek hukum berdasarkan ketentuan hukum dari kesewenangan. ${ }^{12}$ Begitu pula perlindungan hukum bagi rakyat menurut Philipus M. Hadjon meliputi dua hal, yakni:

a. Perlindungan Hukum Preventif (pencegahan), yakni bentuk perlindungan hukum dimana kepada rakyat diberi kesempatan untuk mengajukan keberatan atau pendapatnya sebelum suatu keputusan pemerintah mendapat bentuk yang definitif;

b. Perlindungan Hukum Represif (pemaksaan), yakni bentuk perlindungan hukum dimana lebih ditujukan dalam penyelesaian sengketa. ${ }^{13}$

Tahun 2017, DPR-RI secara resmi mengesahkan RUU Perlindungan Pekerja Migran Indonesia untuk menggantikan UU No. 39 Tahun 2004 tentang Penempatan dan Perlindungan Tenaga Kerja Indonesia di Luar Negeri menjadi UU No. 18 Tahun 2017

11 Soerjono Soekanto, 1984, Pengantar Penelitian Hukum, UI Press, Jakarta, h. 133.

12 Philipus M. Hadjon, 1987, Perlindungan Bagi Rakyat di Indonesia, PT. Bina Ilmu, Surabaya, h. 1-2.

13 Ibid, h. 4-5. 
tentang Perlindungan Pekerja Migran Indonesia. Pengaturan penempatan dan perlindungan TKI ke luar negeri diatur dengan Undang-Undang karena:

1. bekerja merupakan hak asasi manusia yang wajib dijunjung tinggi, dihormati, dan dijamin penegakannya;

2. hak setiap warga negara untuk memperoleh pekerjaan dan penghidupan yang layak baik di dalam maupun di luar negeri sesuai dengan keahlian, keterampilan, bakat, minat, dan kemampuan;

3. dalam kenyataan selama ini TKI yang bekerja ke luar negeri sering dijadikan objek perdagangan manusia, kerja paksa, korban kekerasan, kesewenang-wenangan, kejahatan atas harkat dan martabat manusia, serta perlakuan lain yang bertentangan dengan hak asasi manusia;

4. negara wajib menjamin dan melindungi hak asasi warga negaranya yang bekerja baik di dalam maupun di luar negeri berdasarkan prinsip persamaan hak, demokrasi, keadilan sosial, kesetaraan gender, dan anti diskriminasi;

5. penempatan TKI ke luar negeri perlu dilakukan secara terpadu antara instansi pemerintah baik pusat maupun daerah dan peran serta masyarakat dalam suatu produk hukum yang memadai guna memberikan perlindungan yang maksimal. ${ }^{14}$

Pemerintah berinisiatif untuk merevisi UU No. 39 Tahun 2004 tentang Penempatan dan Perlindungan Tenaga Kerja Indonesia di Luar Negeri sebagai bentuk komitmen untuk melindungi TKI. Dikatakan sejumlah perbedaan UU No. 18 Tahun 2017 tentang Perlindungan Pekerja Migran Indonesia ini dibandingkan dengan Undang-Undang sebelumnya ialah salah satunya bahwa pemerintah daerah dituntut berperan besar untuk mengurus dan melindungi Pekerja Migran Indonesia sejak perekrutan. Itu diwujudkan dengan pembangunan pelayanan satu atap pelayanan Pekerja Migran Indonesia di seluruh kabupaten dan kota, terutama di kantong-kantong TKI.

14 Lalu Husni, 2007, Pengantar Hukum Ketenagakerjaan Indonesia, PT Raja Grafindo Persada, Jakarta, h. 88. 
Terkait dengan keterlibatan pemerintah daerah lainnya ialah dengan membangun Desa Migran Produktif (Desmigratif) yang merupakan suatu program dalam hal perlindungan bagi Pekerja Migran Indonesia yang bekerja di luar negeri dimana bersifat preventif atau pencegahan. Salah satu unsur penting dalam program Desmigratif ini adalah siapapun yang ingin bekerja di luar negeri harus didaftar dan diproses di desa setempat. Program Desmigratif dilaksanakan demi menghindarkan calon Pekerja Migran Indonesia dan juga keluarganya dari proses migrasi yang tidak sesuai dengan prosedur yang ada, berisiko tinggi, ataupun perdagangan manusia (human trafficking).

Desa Migran Produktif yang selanjutnya disebut Desmigratif adalah desa dimana sebagian besar masyarakatnya bekerja di luar negeri, memahami sistem penempatan dan perlindungan tenaga kerja baik di dalam maupun di luar negeri dan mampu membangun usaha secara mandiri yang produktif melalui peran aktif pemerintah desa dan pemangku kepentingan lainnya. Sedangkan Program Desa Migran Produktif yang selanjutnya disebut Program Desmigratif adalah program yang dirancang di desa asal TKI untuk meningkatkan pelayanan dan perlindungan bagi Calon TKI yang akan bekerja ke luar negeri, meningkatkan kemandirian ekonomi dan kesejahteraan utamanya bagi keluarga TKI dan TKI Purna, melalui 4 (empat) kegiatan utama yaitu membangun Pusat Layanan Migrasi, menumbuhkembangkan usaha-usaha produktif keluarga TKI dan TKI Purna, pembentukan community parenting, menumbuhkembangkan koperasi sebagai penguatan usaha produktif, yang pelaksanaannya terintegrasi, saling mendukung dan berkelanjutan. ${ }^{15}$

Program Desmigratif bertujuan untuk meningkatkan perlindungan bagi pekerja migran sejak dari desa. Program ini sengaja dihadirkan di desa-desa yang kebanyakan warganya bekerja sebagai pekerja migran. Dengan program Desmigratif ini, pemerintah desa sebagai unit terkecil struktur pemerintahan akan dilibatkan lebih aktif dalam persoalan pelayanan dan penempatan

15 Kementerian Ketenagakerjaan Republik Indonesia, 2017, "Pedoman Program Desmigratif Desa Migran Produktif", URL: https://docplayer.info /54571746-Pedoman-program-desmigratif-desa-migran-produktif.html, diakses tanggal 17 Mei 2019. 
Pekerja Migran Indonesia, mulai dari sebagai pusat layanan informasi, komunikasi, bagian integral penempatan, hingga koordinasi terhadap perlindungan Pekerja Migran Indonesia sejak pra penempatan, hingga purna penempatan. ${ }^{16}$

Terdapat empat pilar utama program Desmigratif. Pertama, pusat layanan migrasi dimana orang atau warga desa yang hendak berangkat ke luar negeri mendapatkan pelayanan di balai desa melalui peran dari pemerintah desa. Kedua, kegiatan yang terkait dengan usaha produktif untuk membantu pasangan dari TKI yang bekerja di luar negeri agar mereka memiliki keterampilan dan kemauan untuk membangun usaha-usaha produktif. Ketiga, community parenting yaitu kegiatan untuk menangani anak-anak TKI atau anak-anak buruh migran yang diasuh bersama bersamasama oleh masyarakat dalam suatu pusat belajar-mengajar. Pilar keempat yaitu, koperasi usaha untuk penguatan usaha produktif untuk jangka panjang koperasi usaha produktif ini tentunya juga bisa menjadi inisiatif bersama dari masyarakat yang akan didukung oleh pemerintah. ${ }^{17}$

\subsubsection{Jaminan Sosial terhadap Pekerja Migran Indonesia menurut UU No. 18 Tahun 2017 tentang Perlindungan Pekerja Migran Indonesia}

UU No. 18 Tahun 2017 tentang Perlindungan Pekerja Migran Indonesia merupakan suatu bentuk kemajuan apabila dibandingkan dengan UU No. 39 Tahun 2004 tentang Penempatan dan Perlindungan Tenaga Kerja Indonesia Di Luar Negeri. Kemajuan tersebut dapat dilihat dari adanya Bab dan Pasal-pasal spesifik mengenai Perlindungan Buruh Migran, Hak-hak Buruh Migran, Jaminan Sosial, Tugas dan Tanggungjawab Pemerintah Pusat dan

16 Media Indonesia, 2018, "Desmigratif: Perlindungan Pekerja Migran Mulai Dari Desa", URL: https://mediaindonesia.com/read/detail/203147desmigratif-perlindungan-pekerja-migran-mulai-dari-desa, diakses tanggal 21 Mei 2019.

${ }^{17}$ Kementerian Kesehatan Republik Indonesia, 2017, "8 Kementerian Sepakat Tingkatkan Perlindungan TKI Melalui Desa Migran Produktif", URL: http://www.depkes.go.id/pdf.php?id=17053100004, diakses tanggal 19 Mei 2019. 
Pemerintah Daerah, serta Layanan Terpadu Satu Atap Penempatan dan Perlindungan Pekerja Migran Indonesia.

Pasal 29 ayat (1) UU No. 18 Tahun 2017 tentang Perlindungan Pekerja Migran Indonesia menyatakan bahwa "Dalam upaya perlindungan Pekerja Migran Indonesia, Pemerintah Pusat menyelenggarakan Jaminan Sosial bagi Pekerja Migran Indonesia dan keluarganya." Dengan adanya ketentuan tersebut maka Pekerja Migran Indonesia tidak lagi menggunakan asuransi swasta, tetapi BPJS Ketenagakerjaan. Undang-Undang ini lebih menekankan dan memberikan peran yang lebih besar kepada pemerintah dan mengurangi peran swasta dalam penempatan dan Perlindungan Pekerja Migran Indonesia.

Kennet Thomson, seorang tenaga ahli pada Sekretariat Jenderal International Social Security Association (ISSA) di Jenewa, dalam Regional Training Seminar ISSA di Jakarta bulan Juni 1980, mengatakan bahwa "Jaminan sosial dapat diartikan sebagai perlindungan yang diberikan oleh masyarakat bagi anggotaanggotanya untuk risiko-risiko atau peristiwa-peristiwa tertentu dengan tujuan sejauh mungkin untuk menghindari terjadinya peristiwa-peristiwa tersebut yang dapat mengakibatkan hilangnya atau turunnya sebagian besar penghasilan, dan untuk memberikan pelayanan medis dan/atau jaminan keuangan terhadap konsekuensi ekonomi dari terjadinya peristiwa tersebut, serta jaminan untuk tunjangan keluarga dan anak."18

Jaminan sosial dapat diartikan secara luas dan secara sempit. Pengertian luas jaminan sosial meliputi usaha-usaha yang berupa:

a. Pencegahan dan pengembangan, yaitu di bidang kesehatan, keagamaan, keluarga berencana, pendidikan, bantuan hukum, dan lainnya yang dapat dikelompokkan dalam pelayanan sosial (social security).

b. Pemulihan dan penyembuhan, seperti bantuan untuk bencana alam, lanjut usia, yatim piatu, penderita cacat dan berbagai ketunaan yang dapat dikelompokkan dalam pengertian bantuan sosial (social assistance).

18 Sentanoe Kertonegoro, 2000, Jaminan Sosial dan Pelaksanaannya di Indonesia, Mutiara, Jakarta, h. 29. 
c. Pembinaan, dalam bentuk perbaikan gizi, perusahaan, transmigrasi, koperasi, dan lainnya yang dapat dikategorikan dalam sarana sosial (social infra structure).

Sedangkan dalam pengertian yang sempit, jaminan sosial ini meliputi usaha-usaha di bidang perlindungan ketenagakerjaan, yang berupa bantuan sosial dan asuransi sosial. ${ }^{19}$

UU No. 18 Tahun 2017 memberikan perlindungan Jaminan Sosial bagi Pekerja Migran Indonesia yang selama ini dilaksanakan oleh perusahaan asuransi yang tergabung dalam konsorsium asuransi dengan program perlindungan meliputi perlindungan prapenempatan, masa penempatan, dan purna penempatan. Peran perlindungan tersebut saat ini dialihkan dan dilaksanakan oleh Badan Penyelenggara Jaminan Sosial (BPJS) sesuai dengan UU No. 40 Tahun 2004 tentang Sistem Jaminan Sosial Nasional dan UU No. 24 Tahun 2011 tentang Badan Penyelenggara Jaminan Sosial. Untuk risiko tertentu yang tidak tercakup dalam program Jaminan Sosial, BPJS dapat bekerja sama dengan lembaga pemerintah atau swasta.

\section{PENUTUP}

\subsection{Kesimpulan}

1. Upaya pemerintah dalam mewujudkan perlindungan hukum bagi Pekerja Migran Indonesia melalui program Desa Migran Produktif (Desmigratif) merupakan suatu program dalam hal perlindungan bagi Pekerja Migran Indonesia yang bekerja di luar negeri dimana bersifat preventif atau pencegahan, program Desmigratif ini dilaksanakan demi menghindarkan calon Pekerja Migran Indonesia dan juga keluarganya dari proses

19 Zainal Asikin, 2012, Dasar-Dasar Hukum Perburuhan, Rajawali Pers, Jakarta, h. 101. 
migrasi yang tidak sesuai dengan prosedur yang ada, berisiko tinggi, ataupun perdagangan manusia (human trafficking).

2. Jaminan sosial terhadap Pekerja Migran Indonesia menurut UU No. 18 Tahun 2017 tentang Perlindungan Pekerja Migran Indonesia ialah bahwa Pekerja Migran Indonesia tidak lagi menggunakan asuransi swasta, tetapi BPJS Ketenagakerjaan. Undang-Undang ini lebih menekankan dan memberikan peran yang lebih besar kepada pemerintah dan mengurangi peran swasta dalam penempatan dan Perlindungan Pekerja Migran Indonesia.

\subsection{Saran}

1. Hendaknya pemerintah sebagai pihak yang bertanggung jawab dalam hal perlindungan Pekerja Migran Indonesia terus melakukan peninjauan terhadap aturan yang ada sehingga suatu aturan tersebut dapat terus mengalami penyempurnaan demi kebaikan serta agar tidak terulang kembali berbagai kasus menimpa Pekerja Migran Indonesia yang bekerja di luar negeri.

2. Hendaknya di kemudian hari para Pekerja Migran Indonesia dapat belajar dari masalah-masalah yang sebelumnya telah banyak menimpa Pekerja Migran Indonesia lainnya sehingga Pekerja Migran Indonesia dapat lebih berhati-hati dalam bekerja serta memikirkan tujuan jangka panjang untuk kelangsungan perekonomiannya, tidak hanya demi mendapatkan sesuatu yang diinginkan yang bersifat sementara dengan pemikiran yang terburu-buru. 


\section{DAFTAR PUSTAKA}

\section{Buku}

Bambang Sunggono, 2010, Metodelogi Penelitian Hukum, Rajawali Pers, Jakarta.

Lalu Husni, 2007, Pengantar Hukum Ketenagakerjaan Indonesia, PT Raja Grafindo Persada, Jakarta.

Philipus M. Hadjon, 1987, Perlindungan Bagi Rakyat di Indonesia, PT. Bina Ilmu, Surabaya.

Sentanoe Kertonegoro, 2000, Jaminan Sosial dan Pelaksanaannya di Indonesia, Mutiara, Jakarta.

Soerjono Soekanto, 1984, Pengantar Penelitian Hukum, UI Press, Jakarta.

Suratman dan H. Philips Dillah, 2015, Metode Penelitian Hukum, Alfabeta, Bandung.

Zainal Asikin, 2012, Dasar-Dasar Hukum Perburuhan, Rajawali Pers, Jakarta.

Zainuddin Ali, 2014, Metode Penelitian Hukum, Sinar Grafika, Jakarta.

\section{Jurnal Ilmiah}

Erwan Baharudin, 2007, "Perlindungan Hukum Terhadap TKI di Luar Negeri Pra Pemberangkatan, Penempatan, dan Purna Penempatan", Jurnal Universitas Indonesia Esa Unggulan, Jakarta Barat, URL: https://media.neliti.com/media/publi cations / 17928-ID-perlindungan-hukum-terhadap-tki-di-luar -negeri-pra-pemberangkatan-penempatan-dan.pdf

I Wayan Agus Vijayantera, 2016, "Pengaturan Tunjangan Hari Raya Keagamaan sebagai Hak Pekerja Setelah Diterbitkan Peraturan Menteri Tenaga Kerja Nomor 6 Tahun 2016", Jurnal Hukum Kertha Patrika Fakultas Hukum Universitas Udayana, Bali, URL: https://ojs.unud.ac.id/index.php/ kerthapatrika/article/view/30091/18463

Lukas Banu, 2018, "Implementasi Hukum Pasal 35 UndangUndang Nomor 39 Tahun 2004 dalam Program Recognised 
Seasonal Employment", Jurnal Magister Hukum Udayana, Bali, URL: https://ojs.unud.ac.id/index.php/jmhu/article/ view $/ 38603 / 24228$

\section{Internet}

BBC News Indonedia, 2018, Adelina: TKI yang meninggal di Malaysia akibat kurang gizi dan luka-luka membuat 'marah bangsa', https://www.bbc.com/indonesia/trensosial-430448 $\underline{43}$

Kementerian Kesehatan Republik Indonesia, 2017, "8 Kementerian Sepakat Tingkatkan Perlindungan TKI Melalui Desa Migran Produktif", URL: http://www.depkes.go.id/pdf.php?id=1705 $\underline{3100004}$

Kementerian Ketenagakerjaan Republik Indonesia, 2017, "Pedoman Program Desmigratif Desa Migran Produktif", URL: https://docplayer.info/54571746-Pedomanprogramdesmigra tif-desa-migran-produktif.html

Media Indonesia, 2018, "Desmigratif: Perlindungan Pekerja Migran Mulai Dari Desa", URL: https://mediaindonesia.com/read /detail/203147-desmigratif-perlindungan-pekerja-migran-m ulai-dari-desa

Puthut Dwi Putranto Nugroho, 2018, "Kisah Sumiyati, TKI dari Grobogan yang Tewas Dianiaya Majikannya di Arab Saudi", URL: https://regional.kompas.com/read/2018/01/11/0906 0501/kisah-sumiyati-tki-dari-grobogan-yang-tewas-dianiaya -majikannya-di-arab? page $=$ all

Toiskandar, 2017, "Wasni TKI Asal Cirebon Kerap Disiksa dan Tak Digaji Selama 45 Bulan", URL: https://daerah.sindonews.co $\mathrm{m} / \mathrm{read} / 1251784 / 21 /$ wasni-tki-asal-cirebon-kerap-disiksa-d an-tak-digaji-selama-45-bulan-15089874 46

\section{Peraturan Perundang-Undangan}

Undang-Undang Dasar Republik Indonesia Tahun 1945.

Undang-Undang Republik Indonesia Nomor 39 Tahun 2004 tentang Penempatan dan Perlindungan Tenaga Kerja Indonesia di Luar Negeri.

Undang-Undang Republik Indonesia Nomor 18 Tahun 2017 tentang Perlindungan Pekerja Migran Indonesia. 